\title{
Reactions to Total Dose Infusion of Iron Dextran in Rheumatoid Arthritis
}

\author{
KENNETH N. LLOYD, ${ }^{*}$ F.R.C.P. ; PETER WILLIAMS, $†$ M.B., B.CH.
}

\begin{abstract}
Summary: Ten patients with active rheumatoid arthritis were given a total dose infusion of iron dextran for anaemia. One had an immediate anaphylactoid reaction; the other nine had a brief exacerbation of arthralgia and joint dysfunction of up to seven days' duration. The erythrocyte sedimentation rate rose by an average of 23 mm. in one hour (Westergren), but this often took longer than seven days to settle to the preinfusion level.

It is suggested that this response is probably not due to an exacerbation of rheumatoid arthritis but to a delayed hypersensitivity reaction to the dextran portion of the iron dextran complex. This treatment is potentially dangerous in rheumatoid arthritis; we recommend a preliminary test dose and that the infusion be started very slowly under supervision.
\end{abstract}

\section{Introduction}

A study was undertaken as a result of the clinical observation that many patients with rheumatoid arthritis treated with intravenous total dose infusion of iron dextran developed increased arthralgia or even an apparent exacerbation of their arthritis.

Review of the literature revealed a number of reports of interest in this connexion. Clay et al. (1965) gave total dose infusions of iron dextran by Theodoropoulos et al. (1968) eight whom developed anaphylactoid type reactions but only one complained of transient stiffness of arms and neck. In a series of 102 patients with various disorders similarly treated Mehta and Patel (1968) reported joint pains in 14 patients, joint swelling in one patient, and backache in 15 patients; these episodes were all brief. In a series of 106 children with various disorders reported by Thaman and Dogra (1968) one child with rheumatoid arthritis suffered a temporary exacerbation of the condition. In a report of "several thousand" massive infusions of iron dextran by Theodoropculos et al. (1968) eight patients exhibited a syndrome characterized by fever, malaise, arthralgia, and lymphadenopathy which immediately followed infusion and subsided within a few days. The histological picture of a lymph node from one case was thought to indicate an antigen-antibody reaction.

\section{Patients and Methods}

To study this phenomenon, we selected 10 patients with rheumatoid arthritis and anaemia in whom we considered the administration of total dose infusion of iron dextran was indicated by reason of an iron-deficiency anaemia unresponsive to oral iron preparations and a low serum iron concentration. All 10 cases satisfied the criteria of the American Rheumatism Association (1959) for classical or definite rheumatoid arthritis and all had active disease.

Various haematological measurements were carried out but these are not relevant to this paper. We were concerned to assess possible alterations in the patient's arthritic state by the following criteria: (1) erythrocyte sedimentation rate (E.S.R.) by the method of Westergren; and (2) joint function by: (a)

\footnotetext{
* Physician.

† Lately Registrar

Department of Physical Medicine and Rheumatology, United Cardiff Hospitals, Cardiff, CF2 ISZ.
}

hand grip strength, by a rolled sphygmomanometer bag inflated to $30 \mathrm{~mm} . \mathrm{Hg}$, (b) proximal interphalangeal joint size by means of jewellers' rings, (c) joint swelling and/or effusion in wrists, elbows, shoulders, and knees, (d) pain and stiffness in wrists, elbows, shoulders, and knees, $(e)$ range of joint movement, alterations being expressed as a percentage of the original range of movement in wrists, elbows, shoulders, and knees, and $(f)$ walking time for 25 yards ( 23 metres) on the flat under about the same conditions and time of day.

The various measurements were carried out on at least two occasions a few days before administration of the treatment in order to establish a stable baseline. The dose of iron dextran, calculated from the manufacturer's tables correlating the initial haemoglobin level and the patient's weight, was given into the cubital vein in $500-1,000 \mathrm{ml}$. of dextrose $5 \%$ solution with $25 \mathrm{mg}$. of hydrocortisone added. This was administered over a period of 8 to 12 hours.

All measurements were repeated 18 hours after cessation of the infusion and thereafter daily until they stabilized, though in some cases the E.S.R. failed to stabilize before the patients were discharged from the ward.

\section{Results}

Case 10 had a severe anaphylactoid reaction after the administration of only a few drops of the infusion. The patient became flushed, dyspnoeic, and wheezy, with a tachycardia of 130 per minute while the blood pressure fell to unrecordable levels. The infusion was immediately stopped and she was given $100 \mathrm{mg}$. of hydrocortisone intravenously and $0.5 \mathrm{ml}$. of $1 / 1,000$ adrenaline subcutaneously. She was kept warm and flat, and over the next few hours gradually returned to normal.

As only a minimal quantity of iron dextran was administered to this patient the subsequent measurements were discarded. The records of nine patients are therefore presented.

Changes in E.S.R. are given in Table I. All but one case showed a significant rise, which usually occurred within the first few days after total dose infusion, but in Case 5 the maximum rise was delayed until the sixth day. The E.S.R. remained raised for periods varying from three days to six weeks before settling to the levels before total dose infusion. The maximum rise recorded was $36 \mathrm{~mm}$. in one hour, the average being $23 \mathrm{~mm}$. in one hour.

TABLE I.-E.S.R. Changes in mm./hour*

\begin{tabular}{|c|c|c|c|c|c|c|}
\hline \multicolumn{4}{|c|}{ Case No. } & Baseline E.S.R. & Highest E.S.R. & Rise in E.S.R. \\
\hline $\begin{array}{l}1 \\
2 \\
3 \\
4 \\
5 \\
6 \\
7 \\
8 \\
9\end{array}$ & $\begin{array}{l}. \\
\because \\
\therefore \\
\therefore \\
\therefore \\
\therefore\end{array}$ & $\begin{array}{l}\because \\
\because \\
\therefore \\
\therefore \\
\because \\
\therefore \\
\therefore\end{array}$ & $\begin{array}{l}\because \\
\because \\
\because \\
\because \\
\therefore \\
\therefore\end{array}$ & $\begin{array}{l}57 \\
70 \\
48 \\
90 \\
60 \\
64 \\
69 \\
42 \\
78\end{array}$ & $\begin{array}{r}80 \\
103 \\
69 \\
117 \\
96 \\
91 \\
68 \\
63 \\
100\end{array}$ & $\begin{array}{r}+23 \\
+33 \\
+21 \\
+27 \\
+36 \\
+27 \\
+21 \\
+21 \\
+22\end{array}$ \\
\hline & & & & 64 & 87 & 23 \\
\hline
\end{tabular}

The hand grip strength is given in Table II. In four patients there was no alteration in grip and two others showed only slight deterioration. Three patients, however, showed pro- 
nounced deterioration, and in their six hands the average deterioration was $80 \mathrm{~mm} . \mathrm{Hg}$, whereas in the other 12 hands the average deterioration was only $7 \mathrm{~mm}$. $\mathrm{Hg}$.

TABLE II.-Hand Grip Strength In $\mathrm{mm} . \mathrm{Hg}^{*}$

\begin{tabular}{|c|c|c|c|c|c|c|c|c|}
\hline \multicolumn{3}{|c|}{ Case No. } & \multicolumn{2}{|c|}{ Before T.D.I. } & \multicolumn{2}{|c|}{ After T.D.I. } & \multicolumn{2}{|c|}{ Difference } \\
\hline & & & Right & Left & Right & Left & Right & Left \\
\hline $\begin{array}{l}1 \\
2 \\
3 \\
4 \\
5 \\
6 \\
7 \\
8 \\
9\end{array}$ & $\begin{array}{l}. \\
\cdots \\
\cdots \\
\cdots \\
\cdots \\
\therefore \\
\therefore\end{array}$ & $\begin{array}{l}. \\
\cdots \\
\cdots \\
\cdots \\
\cdots \\
\cdots\end{array}$ & $\begin{array}{r}170 \\
80 \\
270 \\
40 \\
110 \\
140 \\
110 \\
38 \\
140\end{array}$ & $\begin{array}{r}300 \\
80 \\
170 \\
50 \\
80 \\
190 \\
150 \\
38 \\
125\end{array}$ & $\begin{array}{r}150 \\
80 \\
120 \\
40 \\
95 \\
70 \\
65 \\
32 \\
145\end{array}$ & $\begin{array}{r}290 \\
80 \\
100 \\
50 \\
55 \\
95 \\
100 \\
30 \\
120\end{array}$ & $\begin{array}{r}-20 \\
0 \\
-150 \\
0 \\
-15 \\
-70 \\
-45 \\
-6 \\
+\quad 5\end{array}$ & $\begin{array}{r}-10 \\
0 \\
-70 \\
0 \\
-25 \\
-95 \\
-50 \\
-8 \\
-5\end{array}$ \\
\hline
\end{tabular}

T.D.I. $=$ Total dose infusion

Only 3 out of 72 proximal interphalangeal joints showed any significant increase in swelling (Table III). In the measurement of ring sizes an observer error of up to three sizes was found to occur; therefore recorded changes within this range were discarded and only differences above this range recorded. Table III also shows that a significant number of medium-sized and

TABLE III.-Foint Pain, Swelling, and Mobility

\begin{tabular}{|c|c|c|c|c|c|c|c|c|c|}
\hline & \multirow{3}{*}{ Case } & \multirow{3}{*}{ No. } & & \multicolumn{3}{|c|}{ Joint Swelling } & \multirow{3}{*}{$\begin{array}{c}\begin{array}{l}\text { Pain } \\
\text { and } \\
\text { Stiff }\end{array} \\
\\
\begin{array}{l}\text { No. of } \\
\text { Joints }\end{array}\end{array}$} & \multicolumn{2}{|c|}{$\begin{array}{c}\begin{array}{c}\text { Loss } \\
\text { of } \\
\text { Mobility }\end{array} \\
\end{array}$} \\
\hline & & & & \multicolumn{2}{|c|}{ P.I.P. Joints } & \multirow{2}{*}{$\begin{array}{l}\text { "Other, } \\
\text { Joints." } \\
\text { No. of } \\
\text { Joints }\end{array}$} & & \multirow{2}{*}{$\begin{array}{l}\text { No. of } \\
\text { Joints }\end{array}$} & \multirow{2}{*}{$\begin{array}{l}\text { Av. for } \\
\text { "Other } \\
\text { Joints." }\end{array}$} \\
\hline & & & & $\begin{array}{c}\text { Size } \\
\text { Change }\end{array}$ & $\begin{array}{l}\text { No. of } \\
\text { Joints }\end{array}$ & & & & \\
\hline $\begin{array}{l}1 \\
2 \\
3 \\
4 \\
5 \\
6 \\
7 \\
8 \\
8 \\
9\end{array}$ & $\begin{array}{l}\ldots \\
\therefore \\
\therefore \\
\therefore \\
\therefore \\
\therefore\end{array}$ & $\begin{array}{l}. \\
\therefore \\
\therefore \\
\therefore \\
\therefore \\
\therefore \\
\therefore \\
\therefore\end{array}$ & $\begin{array}{l}\ldots \\
\ldots \\
\cdots \\
\cdots \\
\cdots \\
\cdots\end{array}$ & $\begin{array}{l}0 \\
3 \\
7 \\
0 \\
0 \\
0 \\
0 \\
0 \\
0\end{array}$ & $\begin{array}{l}0 \\
1 \\
2 \\
0 \\
0 \\
0 \\
0 \\
0 \\
0\end{array}$ & $\begin{array}{c}\text { Nil } \\
6 \\
3 \\
2 \\
2 \\
3 \\
2 \\
\text { Nil } \\
\text { Nil }\end{array}$ & $\begin{array}{l}2 \\
5 \\
8 \\
4 \\
3 \\
4 \\
8 \\
4 \\
2\end{array}$ & $\begin{array}{c}5 \\
4 \\
4 \\
2 \\
1 \\
4 \\
4 \\
4 \\
\text { Nil }\end{array}$ & $\begin{array}{r}26 \% \\
83 \% \\
46 \% \\
50 \% \\
55 \% \\
34 \% \\
47 \% \\
25 \% \\
0 \%\end{array}$ \\
\hline \multicolumn{4}{|c|}{ Average } & 1.0 & 0.3 & 2.0 & 4.4 & 3.1 & $41 \%$ \\
\hline
\end{tabular}

P.I.P. = Proximal interphalangeal.

large-sized joints were worse in regard to pain, stiffness, and swelling, the latter being accounted for by fresh or increased joint effusions, which formed a striking clinical feature. In all but one case there were very significant falls in the range of joint movement, and an average of three large-sized and medium-sized joints per patient were so affected, the average loss of mobility being $41 \%$ per joint.

It is notable that increased proximal interphalangeal joint swelling was not a feature and yet three patients showed pronounced deterioration of grip. In our experience grip strength is affected as much by involvement of the wrist joint as by involvement of the finger joints. This feature explains the above apparently anomalous findings.

Walking time is recorded in Table IV. It was capable of assessment in only seven of the nine cases, and in three of these it deteriorated significantly.

TABLE IV.-Walking Time in Seconds

\begin{tabular}{ccc|c|c|c}
\hline \multicolumn{2}{c|}{ Case No. } & & Before T.D.I. & After T.D.I. & Difference \\
\hline 1 & $\cdots$ & $\cdots$ & 20 & 25 & +5 \\
2 & $\cdots$ & $\cdots$ & 34 & 100 & +66 \\
3 & $\cdots$ & $\cdots$ & 23 & Walking not possible & +17 \\
4 & $\cdots$ & $\cdots$ & \multicolumn{3}{|c|}{} \\
5 & $\cdots$ & $\cdots$ & 90 & Walking not possible & +90 \\
7 & $\cdots$ & $\cdots$ & 32 & 3 paces only & +5 \\
8 & $\cdots$ & $\cdots$ & 55 & 60 & +5 \\
9 & $\cdots$ & $\cdots$ & 13 & 13 & 0 \\
\hline
\end{tabular}

\section{Discussion}

We referred above to 13 reactions reported by Clay et al. (1965); in seven of these resuscitative treatment was required and one case conformed in detail to the anaphylactoid reaction that occurred in our Case 10. Our remaining nine cases showed, in varying degree, a transient exacerbation of their joint pains, swelling, and stiffness mainly in regard to medium and large joints, accompanied by a feeling of general malaise, low-grade fever, and a definite rise in the E.S.R. These symptoms and signs did not come on immediately; usually there was a delay of a day or so, in contrast to the one anaphylactoid reaction developing immediately.

Our original concept had been that intravenous infusion of iron dextran in some way exacerbated the rheumatoid state, though we could not understand the basis for this and had not found any reports of this phenomenon in the available literature. After completion of our studies and during the preparation of this paper, however, Ready and Lewis (1969) reported exacerbation of rheumatoid arthritis in four of a series of seven patients treated with intravenous iron dextran. They thought that the rapid rise in serum iron level might produce increased deposition of iron in the inflamed synovia and so increase inflammation. Our findings indicate that, after infusion, additional physical signs occur far more often in the large-sized and medium-sized joints than in the small ones, whereas if an exacerbation of rheumatoid arthritis had occurred it could be expected to involve a significant number of small joints, which was not the case. This suggests that the findings might be explained on the basis of a delayed hypersensitivity reaction.

It is of interest to note that administration of saccharated oxide of iron intravenously to patients with rheumatoid arthritis by Richmond et al. (1958) caused improvement in their clinical state and a lowering of the E.S.R. without any exacerbation of joint dysfunction but the reverse-namely, significant improvement of functional capacity. On the other hand, sensitivity reactions to intravenous infusion of dextran have been well documented by Zozaya (1932), Kabat and Berg (1953), Maurer (1953), Tarrow and Pulaski (1953), Kabat et al. (1957), Bernstein and Evans (1960), Getsen and Speiggle (1963), and Brisman et al. (1968), which suggests that the dextran and not the iron in the complex is the agent causing the delayed reactions we have noted.

Intradermal tests after infusion on all 10 of our cases, using iron dextran, dextran, and saline as a control did not produce any skin reactions, thus confirming the findings of Tarrow (1955) and Shephard and Vandam (1964), who pointed out that these tests offered little assistance in detecting individuals likely to show systemic reactions.

With regard to the rise in the E.S.R. occurring in our patients, it is noteworthy that Ricketts (1966), conducting invitro experiments, found raised E.S.R. to be directly related to dextran molecule size and hence to viscosity, but dextrans with intrinsic viscosity below 0.25 had no effect on the E.S.R. This finding was in keeping with the clinical observations of Turner et al. (1949), who reported that the infusion of large molecule dextrans caused a constant striking temporary increase in the E.S.R. Iron dextran is complexed from a small molecule dextran of average intrinsic viscosity around 0.06 (British Pharmacopoeia, 1968), and Groden et al. (1968) confirmed that infusion of this substance into patients with iron-deficiency anaemia did not influence the E.S.R. In a further in-vitro experiment we calculated the average in-vivo concentration of iron dextran in our patients following total dose infusion and then set up experiments to mimic this and found no effect on the E.S.R. Thus it seems likely that the rise in the E.S.R. in our cases was part of the picture of a hypersensitivity reaction.

It is clear from our findings and those of Ready and Lewis (1969) that the frequency rate of delayed reactions to intravenous iron dextran is far higher in rheumatoid arthritis than when this treatment is administered in other pathological 
states, as judged by the various reports already quoted. We are now investigating possible reasons for this.

From the practical aspect, as there is no means of forecasting immediate anaphylactoid or delayed reactions, intravenous infusion of iron dextran must be regarded as a potentially dangerous treatment in rheumatoid arthritis. The precaution should be taken of giving an intravenous test dose of $2 \mathrm{ml}$. of the solution so as to detect anaphylactoid reactors; this can then be followed by the total dose infusion, which should b? begun very slowly under close clinical observation, including frequent blood pressure checks, in order to discover early signs of anaphylactoid shock.

\section{REFERENCES}

American Rheumatism Association (1959). Annals of the Rheumatic Diseases, 18, 49.

British Pharmacopoeia, 1968, p. 529. London, Pharmaceutical Press.

Bernstein, E. F., and Evans, R. L. (1960). fournal of the American Medical Association, 174, 1417.
Brisman, R., Parks, L. C., and Haller, J. A. (1968). Fournal of the American Medical Association, 204, 824.

Clay, B., Rosenberg, B., Sampson, N., and Samuels, S. I. (1965). British Medical fournal, 1, 29.

Getsen, J. H., and Speiggle, W. (1963). Archives of Internal Medicine, 112,168 .

Groden, B. M., Whitelaw, J., and Will, G. (1968). Postgraduate Medical fournal, 44, 433 .

Kabat, E. A., and Berg, D. (1953), fournal of Immunology, 70, 514

Kabat, E. A., Turino, G. M. Tarrow, A. B., and Maurer, P. H. (1957) fournal of Clinical Investigation, 36, 1160 .

Maurer, P. H. (1953). Proceedings of the Society for Experimental Biology and Medicine, 83, 879 .

Mehta, B. C., and Patel, J. C. (1968). Indian fournal of Medical Sciences 22, 1

Ready, P. S., and Lewis, M. (1969). Arthritis and Rheumatism, 12, 454. Richmond, J., Roy, L. M. H., Gardner, D. L., Alexander, W. R. M., and Duthie, J. J. R. (1958). Annals of the Rheumatic Diseases, 17, 406.

Ricketts, C. R. (1966). British Medical fournal, 2, 1423.

Shephard, D. A. E., and Vandam, L. D. (1964). Anesthesiology, 25, 244.

Tarrow, A. B. (1955). Anesthesiology, 16, 598.

Tarrow, A. B., and Pulaski, E. J. (1953). Anesthesiology, 14, 359.

Thaman, O. P., and Dogra, K. N. (1968). Indian fournal of Pediatrics, 35,1 .

Theodoropoulos, G., Makkous, A., and Constantoulakis, M. (1968). fournal of Clinical Pathology, 2i, 493.

Turner, F. P., Butler, B. C., Smith, M. E., and Scudder, J. (1949). Surgery, Gynecology and Obstetrics, 88, 661 .

Zozaya, J. (1932). fournal of Experimental Medicine, 55, 353.

\title{
Controlled Clinical Trial of Ergotamine Tartrate
}

\author{
W. E. WATERS,* M.B., B.S., D.I.H.
}

British Medical fournal, 1970, 2, 325-327

\begin{abstract}
Summary: A double-blind controlled clinical trial of cross-over design for the treatment of headache was conducted in 88 women identified during a community survey as having headaches with the features of migraine. Of 79 subjects who completed the trial, 40 benefited from oral ergotamine tartrate and 46 benefited from the placebo. There was no evidence that ergotamine in doses of 2 or $3 \mathrm{mg}$. was more effective than the placebo. Ergotamine aggravated the attack significantly more often than the placebo. Neither the colour of the tablets nor the order of therapy significantly affected the results of the treatment.
\end{abstract}

129 women were identified by questionaries for consideration for the trial. These women had headaches with at least two of the following features: unilateral distribution, warning of attack, and accompanying nausea. Forty-one were found unsuitable for the trial (Table I). In a separate investigation, 43 of the women who completed the trial were examined by a neurologist (Waters and O'Connor, 1970)-31 were diagnosed clinically as migraine (group A) and in 12 the diagnosis was uncertain or of non-migrainous headaches (group B). The other subjects (group C) had all three migraine features listed above, and this correlates with a diagnosis of migraine, based on a conventional slinical interview, in nearly $90 \%$ of cases (Waters and O'Connor, 1970).

\section{Introduction}

Since ergotamine tartrate was first used in the treatment of migraine over 40 years ago it has steadily gained favour and is now regarded as the most useful single drug in the treatment of attack (Wolff, 1963; Dunlop, 1969). Indeed relief by eryotamine is often considered a useful criteria in the diagnosis of migraine (Friedman and Merrit, 1959; Ostfeld, 1963) as it is said to give little relief in other headaches (Brazeau, 1965) and may aggravate muscle-contraction headache (Wolff, 1963). The differentiation of migraine from musclecontraction headache is not always easy and in fact was found to be especially difficult during studies of headache in random samples of the general population (Waters, 1970). It was therefore hoped ta use the response to ergotamine as a method of validating a questionary designed for use during epidemiological studies of headache. A clinical trial of oral ergotamine tartrate against a placebo for the treatment of attacks was conducted in 88 women. These women were identified from questionaries during a community study as having headaches with the features of migraine.

\section{Methods}

Selection of Subjects.-During a community survey, in which over $86 \%$ of women aged 20 to 64 years living in a defined area of the Rhondda Fach (Glamorgan) were seen, * Member of Scientific Staff, Medical Research Council's Epidemiology
Unit (South Wales), Cardiff CF2 3AS.
TABLE I.-Exclusions Before and During Clinical Trial

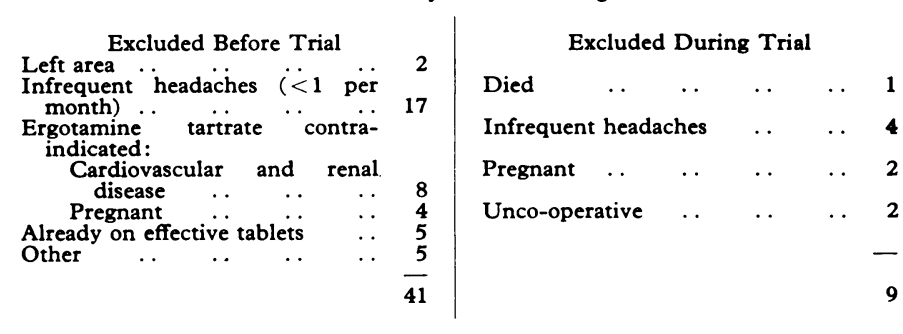

\section{Conduct of Trial}

The trial was double-blind and of cross-over design. The subjects received tablets of ergotamine $(1 \mathrm{mg}$.) and placebo (lactose) in random order for periods of eight weeks each. The tablets were green or white and the order in which the colours were given was randomized. Tablet colour was independent of contents to prevent colour preferences being confused with pharmacological effect (Asher, 1948). Tablets were all of the same size. With a balanced experimental design each treatment combination (Table II) occurred randomly three times within blocks of 12 .

The subjects were told to swallow two tablets as early as relief was not obtained after half an hour. After a further possible in each attack. Another tablet might be taken if 